\title{
MULTI PURPOSE EVAPORATIVE COOLING SYSTEM
}

\author{
Nikhil Vanraj Thakare ${ }^{1}$ \\ ${ }^{l}$ Mechanical Engineering Department, SSVPS's B.S.Deore College of Engineering, Dhule, Maharashtra, INDIA
}

\begin{abstract}
This paper shows study of multi-purpose evaporative cooler. It has basically two stage of cooling - first is sensible cooling $\left(Q_{\text {precool }}\right)$ and second one is evaporative cooling $\left(Q_{\text {evaporative }}\right)$. An Evaporative Cooler produces effective cooling by combining the natural process - water evaporation with simple, reliable air-moving system. During study it is proved that Evaporative Cooling has versatile applications. The paper shows the study of air cooler cum cold storage cum water cooler has been developed which can be utilized for the purpose of air cooling, drinking water cooling and cold storage for preserving the perishable food stuff like storing a vegetables, fruits, medicines, bakery products, chocolates etc. This multipurpose action is happens without altering the performance of Dessert Cooler. A small size Dessert Cooler can cool the water up to Wet Bulb Temperature (WBT) of outside air as well as could store vegetables for considerable period of time. The damper is used to control the humidity level inside the room as per the requirement.
\end{abstract}

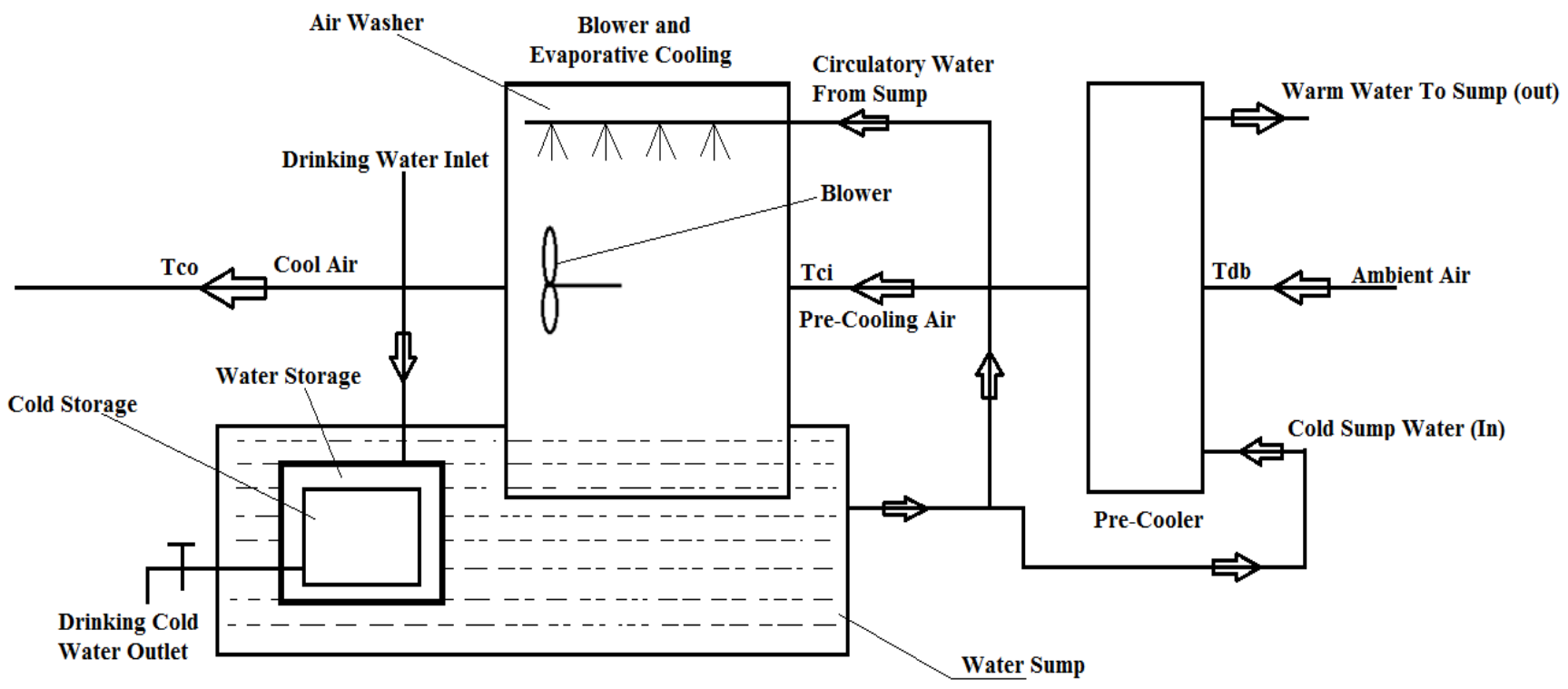

Fig.1 Schematic presentation of Multi-purpose Evaporative Cooling System

\section{NOMENCLATURE}

DBT $=$ Dry Bulb temperature ${ }^{0} \mathrm{C}$

$\mathrm{WBT}=$ Wet Bulb Temperature ${ }^{0} \mathrm{C}$

$\mathrm{Q}_{\text {precool }}=\dot{\mathrm{ma}} * \mathrm{Cp} *\left(\mathrm{~T}_{\mathrm{db}}-\mathrm{T}_{\mathrm{ci}}\right) \mathrm{KJ}$

$\mathrm{Q}_{\text {evaporative }}=\dot{\mathrm{ma}} \mathrm{a}^{*} \mathrm{Cp} *\left(\mathrm{~T}_{\mathrm{ci}}-\mathrm{T}_{\mathrm{co}}\right) \mathrm{KJ}$

$\mathrm{Q}_{\text {total }}=\mathrm{Q}_{\text {precool }}+\mathrm{Q}_{\text {evaporative }}$

Tbd= Outdoor Dry Bulb Temperature ${ }^{0} \mathrm{C}$

$\mathrm{Twb}=$ Outdoor Wet Bulb Temperature ${ }^{0} \mathrm{C}$

SAT $=$ Supply Air Temperature ${ }^{0} \mathrm{C}$

Thi $=$ Temperature of Hot Air Inlet ${ }^{0} \mathrm{C}$

Tho $=$ Temperature of Hot Air Outlet ${ }^{0} \mathrm{C}$

$\mathrm{Tci}=$ Temperature of Cooling Air inlet ${ }^{0} \mathrm{C}$

$\mathrm{Tco}=$ Temperature of cooling Air outlet ${ }^{0} \mathrm{C}$

$\mathrm{CFM}=$ Cubic Feet per minute

$\mathrm{W}=$ Humidity $\mathrm{kg} / \mathrm{kg}$ of dry air

\section{GREEK SYMBOLS}

$\epsilon=$ Effectiveness \% 


\section{INTRODUCTION}

The paper presents Multipurpose Cooling Apparatus including direct/indirect evaporative cooling. The Apparatus includes a heat exchanger, an evaporative pad, a damper, a water cooler, a food storage and induced blower. The Literature 1 stands for the ambient air which is first precooled sensibly i.e. in heat exchanger and then humidified in Evaporative pad chamber, the pre-cooling reduces the temperature of air from $42^{\circ} \mathrm{C}$ to $38^{\circ} \mathrm{C}$ from result and this evaporative cooling system also use for the preservation of fresh vegetables and cool the portable water temperature without altering the performance of dessert cooler. This multipurpose cooler is use in the areas where climatic conditions are dry and hot and where refrigeration and cooler are not economical to run for the separate aspects. The Literature 2-4 shows the pre-cooled air flow is in direct contact with the water film so the Dry Bulb Temperature (DBT) is reduces by evaporation of water in air stream. The drop in Dry Bulb Temperature (DBT) shows how effectively cooling is done. The cooling efficiency is depends on the material of pad, water consumption and air velocity. The effective air cooling reduces the excessive temperature rise and humidity level in room while it will supply direct into the room during summer. Evaporative cooler produces maximum cooling when they subject to natural evaporation process by moving water. This technology is an energy-efficient one and use only onefourth of the energy compared to other conventional equipment.

\section{EXPERIMENTATION}

The experiment consist of the regular dessert cooler having condenser coil on backside with other two sides and uppermost side cover with (insulated) stainless steel plating including water sump in it. The overall dimension of cooler is $65 \times 75 \times 115 \mathrm{~cm}$. In the height of $115 \mathrm{~cm} 25 \mathrm{~cm}$ is the height of water sump from bottom side of cooler. The condenser coils are situated above water sump on backside of cooler and water as a coolant passing through it by using pump. The dimension of water sump is $65 \times 75 \times 25 \mathrm{~cm}$. Evaporative pad section is kept within the distance of 52.5 $\mathrm{cm}$ from left hand side. Over the evaporative pad air washer is installed to make direct evaporative cooling. While, in the remaining distance of $12.5 \mathrm{~cm}$ the moisture controlling damper is installed. It comes in action when Wet Bulb Temperature (WBT) inside the room is increases. Because of it the dry pre-cool air directly mixed with evaporative cool air. By mixing of these two airs only dry cool air supplied to the room and maintains the WBT constant. To suck the completely cooled air, the high speed induced blower is used. To reduce the velocity of blower to the normal desert cooler blower, the velocity reduction duct is fitted on the inlet of induced axial blower in order to reduce the velocity 5 times than the velocity of blower and indirectly it reduces the extreme noise of the blower. Inside the sump, the food storage tank is fitted of dimension $28 \mathrm{X}$ $40 \times 18 \mathrm{~cm}$. The clearance of $1 \mathrm{~cm}$ on all the sides of food storage tank is provided in ordered to store a drinking water in it. As soon as the water in the sump tank is cooled because of direct and indirect evaporative cooling, it cools the portable water tank while this cooled water use to reduce the temperature of food storage tank to preserve the perishable food stuff. To measure the performance of multipurpose evaporative cooler the thermocouples are inserted to detect the temperature differences between various points. There are 10 thermocouples are used T1, T2, T3, T4, T5, T6, T7, T8, T9, T10 to measure temperature of ambient air, after pre cooler, after evaporator, pre cooler inlet, pre cooler outlet, sump water, food storage, water cooler inlet, water cooler outlet and room temperature respectively.

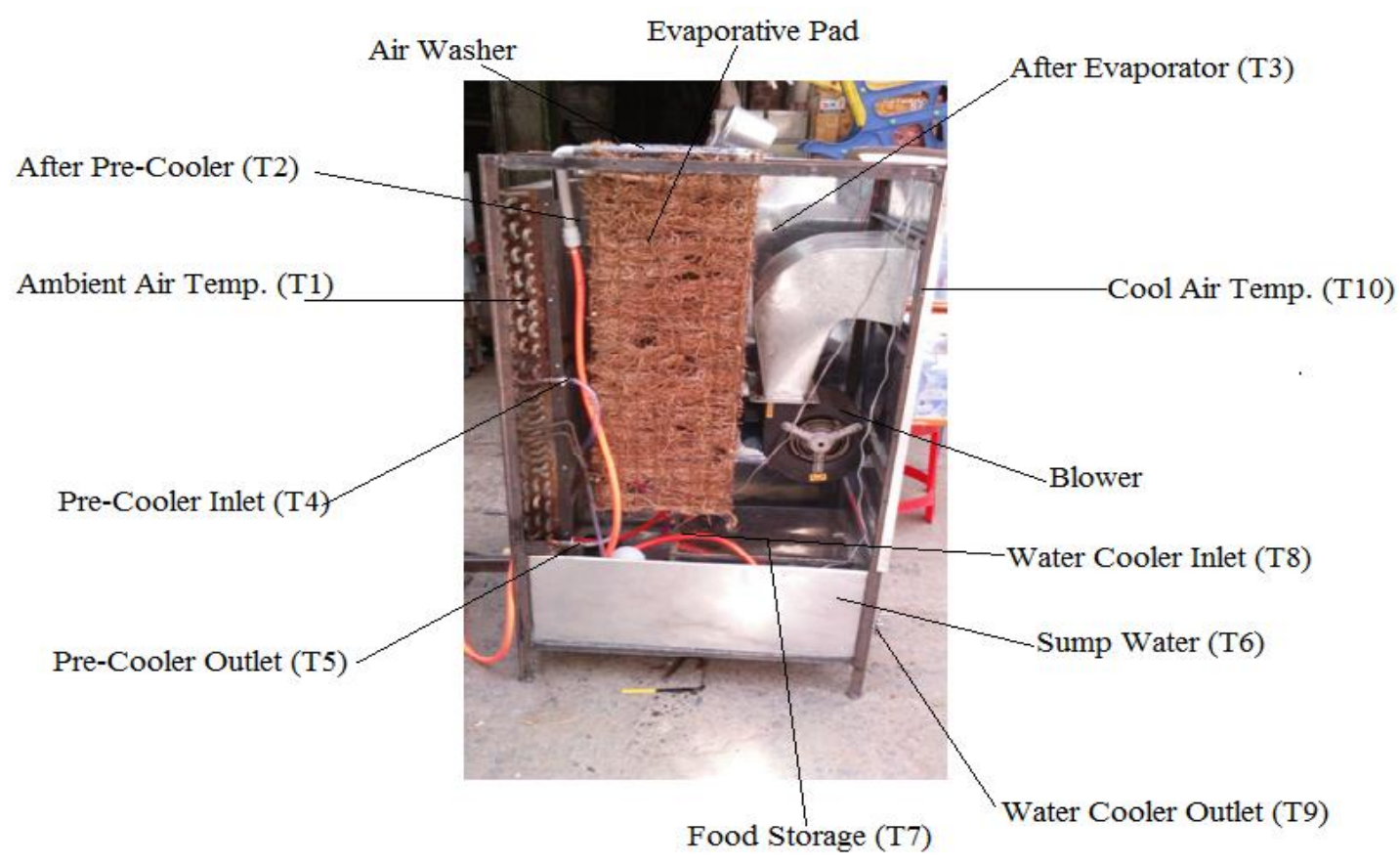

Fig.2 Multi-purpose Evaporative Cooling System 


\section{RESULTS AND DISCUSSION}

$\mathrm{T} 1, \mathrm{~T} 2, \ldots \ldots, \mathrm{T} 10$ are the number of thermocouples attached at the various locations of the cooler. Graph 1 represents the water temperature variation with respect to Time. T4, T5, T6, T8, T9 are the temperature of water at pre-cooler inlet, at pre-cooler outlet, temp. of sump water, temp. of drinking water inlet, temp. of drinking water outlet respectively. Similarly graph 2 represents the air temp. variation with respect to time. Here T1, T2, T3, T10 which the temp. of air outside i.e. ambient air, temp. of air after pre-cooler, temp. of air after evaporator and temp. of air inside the room respectively are being considered. These two graphs shows the actual performance of multipurpose cooler at the point of starting and shows the results as shown below.. At the start, $\mathrm{T} 1$ is $41.1^{\circ} \mathrm{C}$ and $\mathrm{T} 10$ becomes $30^{\circ} \mathrm{C}$. Therefore, there is around $12^{\circ} \mathrm{C}$ difference in temp. As the time passed, there is an variation between outside air temp. and inside room temp.

\section{Temperature of water Vs Time}

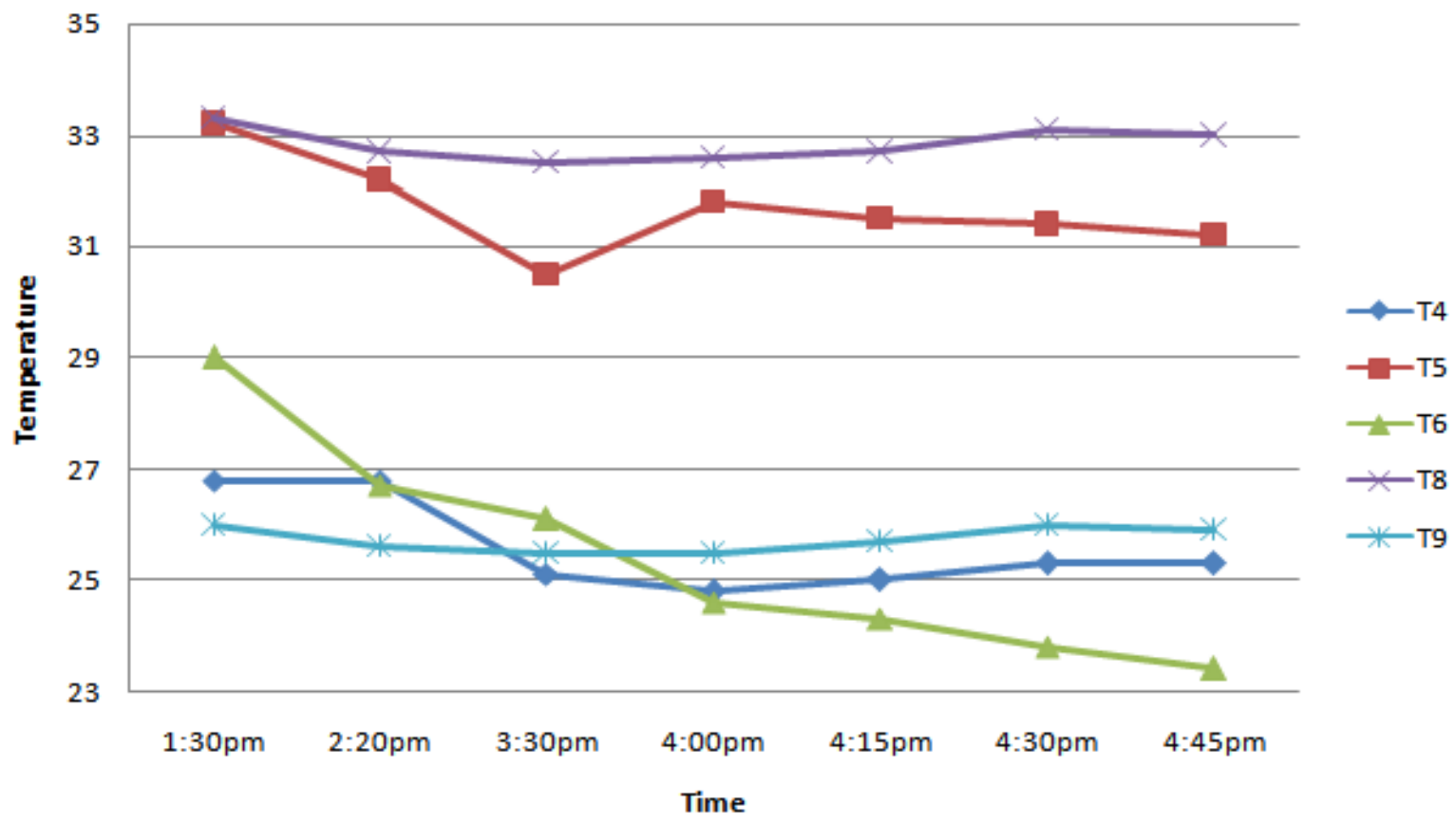

Temperature of air Vs Time

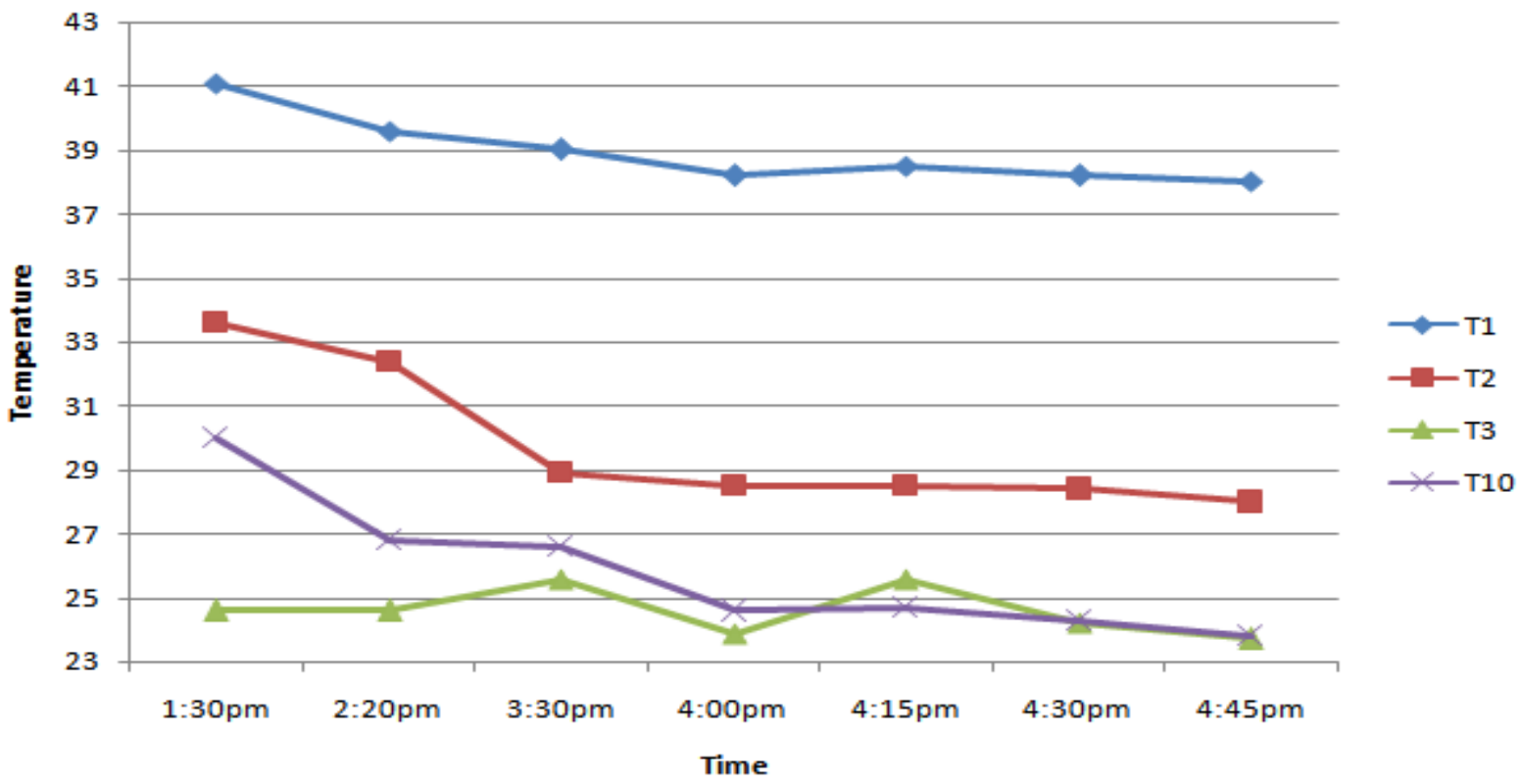




\section{Psychometric Chart}

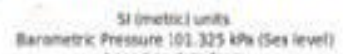

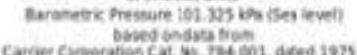

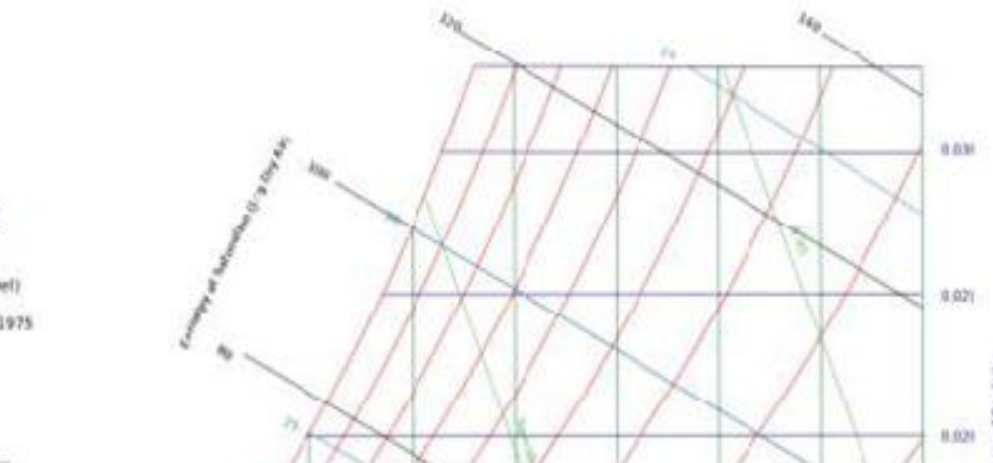

1-2 DIRICTEVAPORATIE COOUNG

1.-2.2" INDIFCT-DIRECT EVAPORITVE COOHNG (TYO ST AGE COOH ING:



Fig 6: Psychometric representation on performance of multipurpose evaporative cooler

\section{CONCLUSION}

On the basis of results obtained from present study, following conclusions are drawn

The Multi-Purpose Evaporative Cooler is generally has major functions like it will control the humidity and temperature for wide range, as a cold storage to store the food stuff like a vegetables, bakery products, chocolates, medicines etc. The main medicines which can be stored in the temperature range of $22-27{ }^{\circ} \mathrm{C}$ and the food stuff can be stored for a period of time without any decay in their properties shows in figure 7 and to cool drinking water.

- This system performs better than the normal desert cooler in term of utilization of cooling effect for cooling of air, cooling of water and cold storage.

- Humidity of cooled air coming out from the MPEC is low as compared to conventional desert cooler.

- By performing experiment, the most predominant factor is it requires less amount of water than conventional desert cooler. The overall percentage of saving as compared to desert cooler is $53.33 \%$.

- Finally, it can be concluded that the system is not costly as air conditioner and more energy efficient than air conditioner. 


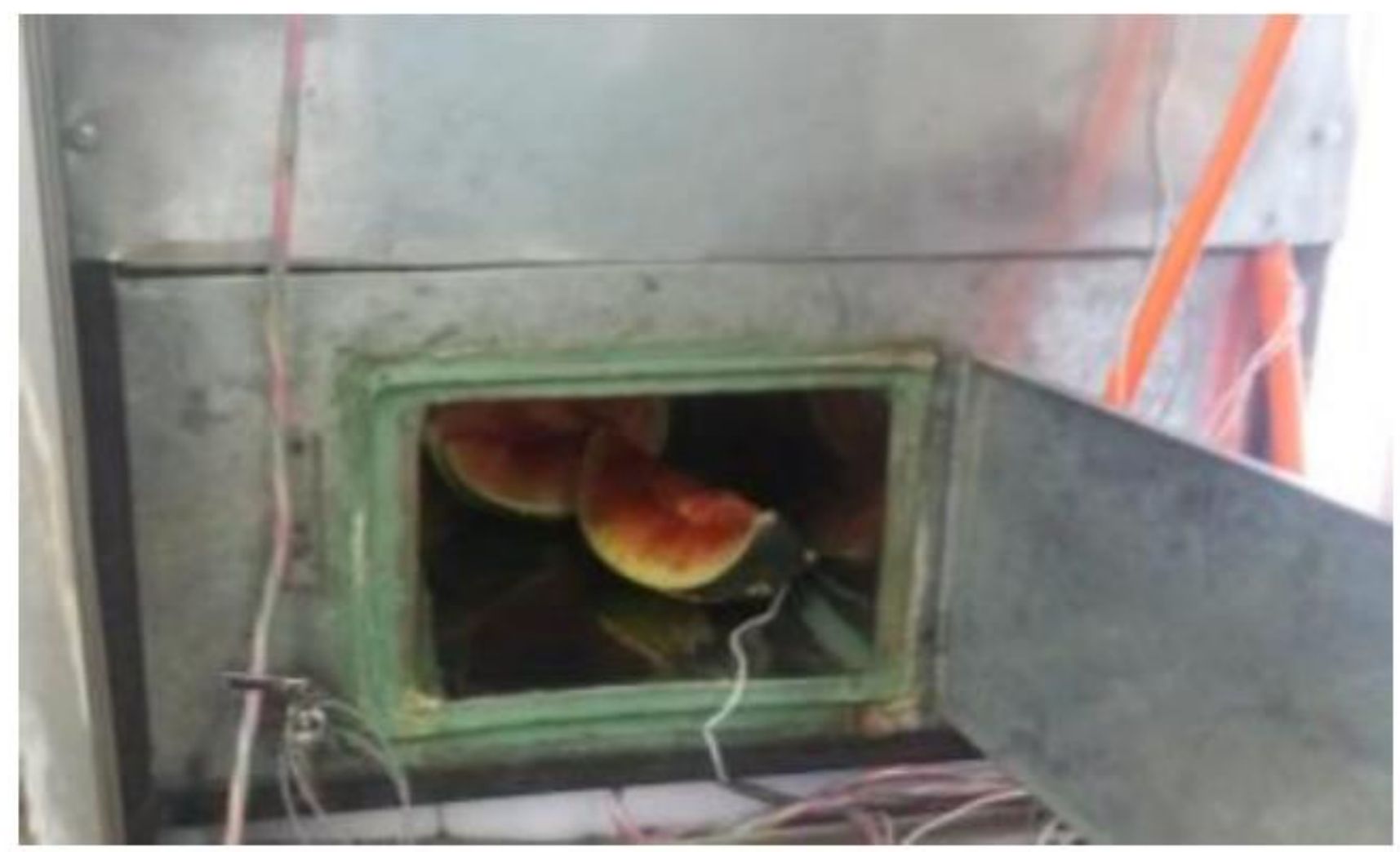

Fig 6: Food Storage containing Watermelon and tomatoes

\section{REFERENCES}

[1] Poonia M.P., Bharadwaj A., Upendra Pandel, Jethoo A.S. Design and Development of Energy Efficient Multi-Utility Dessert Cooler, Universal Journal of Environmental Research and Technology, Available Online at www.enviromentaljournal.org (c) All Reserved 2011 Volm 139-44

[2] Kumar Saurav, Singh Hari Kumar "Modified Indirect Evaporative Cooling System For Dessert Cooler" ISSN:2348-4098. Vol 2 Issue 8 Nov-Dec 2014 Kumar Saurav Et Al. Date of Publication: Jan 03, 2014

[3] Khond Vivek W., "Experimental investigation of desert cooler performance using four different cooling pad materials" American Journal Of Scientific And Industrial Research (C) 2011, Science Huß, http://www.scihub.org/AJSIR ISSN:2153649Xdoi:10.5251/ajs ir.2011.2.3.418.421

[4] Sujith K S, Gokul K Manoj, Amal R. "Development of Economic Evaporative Air Cooling System" IJRET: International Journal of Research in Engineering and Technology 7308 eISSN: 2319-1163 INCEPTION-2015 Apr-2015, Available @ http://www.ijret.org

[5] Evaporative Cooling: Saving Energy in More Ways Than Ever Innovations in Evaporative cooling and water Treatment Energy Design Resources e-News, April 2010

[6] http://en.wikipedia.org/wiki/Airconditioning
[7] Evaporative cooling design guidelines manual, Energy Conservation and Management Division Energy, Minerals and Naturals Resources Department.

[8] Kamaldeen O.S, Anugwom Uzoma, Olyemic F.F and Awagu E.F, "Effect of NSPRI tin-inpot compared with pot-in-pot evaporative cooler on the stored fruits", International Journal of Engineering and Technology, 2(1) (2013) 63-69 (OScience Publishing Corporation www.sciencepubco.com/index.php/IJET

[9] Evaporative Cooler- Wikipedia, the free encyclopedia

[10] Sharma Ashok Kumar, Bishnoi Pawan "Development and testing of natural draught dessert cooler" International Journal of Science and Engineering Applications (IJSEA) Volume 2 Issue 1, 2013, ISSN2319-7560(online)

[11] Kothare Chaudhuri B., Borkar Nitin B., "Modified Desert Cooling (MDC)", Kothare Chandrakant B et al. / International Journal of Engineering and Technology Vol.3 (2), 2011, 166-172. 